\title{
Estimation of canopy water storage capacity from sap flow measurements in a Bornean tropical rainforest
}

\author{
Tomonori Kume ${ }^{\mathrm{a}, *}$, Odair J. Manfroi ${ }^{\mathrm{b}}$, Koichiro Kuraji ${ }^{\mathrm{c}}$, Nobuaki Tanaka ${ }^{\mathrm{c}}$, \\ Toshinobu Horiuchi ${ }^{\text {b,d }}$, Masakazu Suzuki ${ }^{\text {b }}$, Tomo'omi Kumagai ${ }^{\text {e }}$
}

\author{
a Kasuya Research Forest, Kyushu University, Sasaguri, Fukuoka 811-2415, Japan \\ b Graduate School of Agricultural and Life Sciences, The University of Tokyo, Bunkyo-ku, Tokyo 113-8657, Japan \\ c University Forest in Aichi, The University of Tokyo, Seto, Aichi 489-0031, Japan \\ d Nippon Express Co. Ltd., Minato-ku, Tokyo 105-0021, Japan \\ e Shiiba Research Forest, Kyushu University, Shiiba-son, Miyazaki 883-0402, Japan
}

Received 2 November 2006; received in revised form 10 January 2008; accepted 16 January 2008

\section{KEYWORDS \\ Sap flow; \\ Water storage capacity; Aerodynamic resistance; Canopy drying time}

\begin{abstract}
Summary Canopy water storage capacity $(\mathrm{Sc})$ is a key parameter for estimations of rainfall interception using a big-leaf model (BLM). This study proposes a simple method for estimating Sc. The crucial factor in this method is the canopy drying time (or wet canopy duration) after rainfall. The time can be estimated from sap flow measurements in accordance with an earlier study of ours in a Bornean tropical rainforest. By using the estimated canopy drying time to calibrate a BLM for rainfall interception, we derived Sc. This method could also provide aerodynamic resistance $(\mathrm{Ra})$. To validate our estimations, the derived parameters Sc and Ra were compared to Sc and Ra determined independently by a method based on net rainfall measurements on an event basis and on wind profile measurements, respectively. The parameters in our method $\left(\mathrm{Sc}=0.7 \mathrm{~mm}, \mathrm{Ra}=14 \mathrm{~s} \mathrm{~m}^{-1}\right)$ were shown to correspond well to the values determined by independent methods. Furthermore, the method proposed in this study is applicable to tropical forests where short canopy drying times can be expected after rainfall; that is, if the cloudy weather after rainfall becomes sunny within $250 \mathrm{~min}$.

(c) 2008 Elsevier B.V. All rights reserved.
\end{abstract}

\section{Introduction}

In tropical forests in Southeast Asia, where relative deforestation rates are among the world's highest (Houghton and Hackler, 1999), predicting the consequences of land-use changes for water cycling is a critical issue. For this, single 3119.

E-mail address: kumett@forest.kyushu-u.ac.jp (T. Kume).

0022-1694/\$ - see front matter (c) 2008 Elsevier B.V. All rights reserved. 
layer biosphere-atmospheric models such as big-leaf models (BLM) are promising tools for understanding how forest water cycling responds to possible shifts in land-use (Landsberg and Gower, 1997). In tropical forest ecosystems, rainfall interception, which accounts for $10-40 \%$ of the total amount of annual rainfall (Kuraji and Tanaka, 2003), is a major hydrologic component in determining the water budget of forest areas. To predict rainfall interception in tropical forests using BLM, a prerequisite is the determination of the canopy water storage capacity $(\mathrm{Sc})$ of forest stands, a key parameter in BLM (e.g., Rutter et al., 1975).

Sc depends on the stand characteristics such as species composition and the surface area index, and has been reported to range between 0.6 and $1.3 \mathrm{~mm}$ in tropical rainforests (e.g., Lloyd et al., 1988; Schellekens et al., 2000). To estimate Sc, three conventional methods are commonly used: net rainfall measurements on an event basis (Klaassen et al., 1998), scaling-up (Liu, 1998; Llorens and Gallart, 2000), and remote sensing (Bouten et al., 1996). Because of its simplicity, the net rainfall method based on event measurements of rainfall, throughfall and stemflow is often used to estimate Sc. However, it has been reported that this method is difficult to apply in regions with high spatial variability of throughfall, such as in tropical forests (Lloyd et al., 1988; Manfroi et al., 2006). In the scaling-up method, Sc can be scaled up from surface area indices and the corresponding specific water storage capacity of each part of the trees. However, this method is destructive. Remote sensing methods such as those based on gamma-rays and microwaves allow for continuous monitoring of canopy wetness, but involve complex calibrations and are expensive to implement.

This study proposes a simple method for estimating Sc in tropical forests using sap flow measurements, a robust technique that can be conducted cheaply and interfaced readily through data loggers for long-term monitoring. With this method, the crucial factor is the estimation of canopy drying time (or wet canopy duration) after rainfall. Here, canopy drying time after rainfall was estimated using sap flow measurements taken from our earlier study conducted in a Bornean tropical rainforest (Kume et al., 2006). By using the estimated canopy drying time to calibrate a BLM for rainfall interception, we could derive Sc in this study. Aerodynamic resistance $(\mathrm{Ra})$ could also be derived with this method. To validate our estimations of Sc and Ra, those were compared to Sc and Ra determined independently by conventional methods based on net rainfall and wind profile measurements in a Bornean tropical rainforest. We also discuss practical limitations of the simple method we propose in this study.

\section{Theory}

\section{Definition of canopy drying time}

Transpiration decreases during canopy wetting (e.g., Rutter et al., 1975; Watanabe and Mizutani, 1996) and can be monitored continuously by sap flow measurements (Bosveld and Bouten, 2003; Takanashi et al., 2003). Therefore, in our earlier study sap flow velocities were used to detect the integrated canopy wetness condition (Kume et al., 2006). At this site, when sap flow velocity after rainfall becomes equal to the value of the sap flow velocity assumed for bright days, it can be thought that the effect of leaf wetness on transpiration has been removed and that the canopy is completely dry. Sap flow velocity measured at the same time on bright days can have almost the same value throughout the year at this a seasonal site; thus, the lower sap flow velocity after rainfall than that expected on a bright day is thought to be due to the canopy wetness at this site where cloudy weather after rainfall tends to abruptly change to sunny (Kume et al., 2006).

In our earlier study, we estimated canopy drying time by sap flow velocities (CDTobs) (a more complete background and definition of the CDTobs is available in Fig. 3 in Kume et al. (2006)). In our studies, CDTobs is defined as the period from the time rain ceased $(A)$ to a specific time $S$ in each rain event (see Fig. $4 a$ and e). Here, $S$ is the time when sap flow velocity after rainfall exceeds the average minus the standard deviation of the sap flow velocity averaged over 20 bright days. This study assumes that a wet canopy has dried out at the time $S$. We also confirmed that almost the same results were found using other definitions of $S$ (Kume et al., 2006). Twenty bright days were selected for the measurement period as representing no-rain and cloudless days; however, the ' 20 days' was an arbitrary number.

In this study, we used three criteria to select target rain events to derive CDTobs: (1) rainfall ceased in the daytime from $06: 00$ to $17: 00$. (2) The period of no rainfall between each rain event exceeded $2 \mathrm{~h}$. (3) Total rainfall for each rain event exceeded a threshold of $1.5 \mathrm{~mm}$. There are two reasons for the three criteria; one is that sap flow velocity varies markedly during the daytime. The other is that it was essential to deal with rain events in which the canopy is fully wet at the time rainfall ceased. The threshold of $1.5 \mathrm{~mm}$ was enough rainwater to guarantee a fully wet canopy at the time rainfall ceased (e.g., Lloyd et al., 1988; Schellekens et al., 2000). To include as many rain events as possible and still guarantee a fully wet canopy at the time rainfall ceased, we considered canopy drying during a short no-rain period as insignificant. In our study, we included rain events with no-rain periods of $2 \mathrm{~h}$ or less, which is shorter than the no-rain periods used in other studies on tropical rainforests (e.g., Lloyd et al., 1988; Schellekens et al., 2000; Manfroi et al., 2004). Furthermore, we confirmed that sap flow velocities remained nearly zero during our target rain events. This suggests that almost all leaf surfaces are wetted during rain events, and that canopy drying during the short no-rain periods has little impact on the wet canopy conditions at the time rain ceases. As a result, we could derive CDTobs from 22 rain events in the period between June 2001 and March 2002.

\section{Determining optimal parameters of Sc and Ra}

Canopy drying time after rainfall is the period needed to evaporate water storage on leaves after rainfall. When we assume that evaporative energy is completely consumed to evaporate water storage on leaves during the period of canopy drying time after rainfall and that transpiration is negligible during that period, canopy drying time after rainfall can be expressed as follows: 
CDTcalc $=\frac{S C}{\overline{E i}}$

in which

$\overline{E i}=\frac{\Delta(\overline{\mathrm{Rn}}-G)+\rho \cdot C p \cdot \overline{\mathrm{VPD}} / \mathrm{Ra}}{(\Delta+\gamma) \lambda}$,

where CDTcalc is the calculated canopy drying time after rainfall $(\mathrm{min})$, Sc is the canopy water storage at the time rainfall ceases $(\mathrm{mm})$, and $\overline{E i}$ is the mean evaporation rate from a wet canopy after rainfall $(\mathrm{mm} / \mathrm{min}), \Delta$ is the slope of the saturation vapor pressure function $\left(\mathrm{hPa} \mathrm{K}^{-1}\right), \overline{\mathrm{Rn}}$ is the mean net radiation during the canopy drying period $\left(\mathrm{W} \mathrm{m}^{-2}\right), G$ is the soil heat flux ( $\left.\mathrm{W} \mathrm{m}^{-2}\right), \rho$ is the air density $\left(\mathrm{kg} \mathrm{m}^{-3}\right), C p$ is the specific heat of air $\left(\mathrm{J} \mathrm{kg}^{-1} \mathrm{~K}^{-1}\right), \overline{\mathrm{VPD}}$ is the mean vapor pressure deficit of the air during the canopy drying period $(\mathrm{hPa}), \mathrm{Ra}$ is the aerodynamic resistance for heat and water from vegetation $\left(\mathrm{s} \mathrm{m}^{-1}\right), \gamma$ is the psychrometer constant $\left(\mathrm{hPa} \mathrm{K}^{-1}\right)$, and $\lambda$ is the latent heat of water vaporization $\left(\mathrm{J} \mathrm{g}^{-1}\right) . G$ was negligible at this study site (Sato et al., 2004). Sc is equivalent to the canopy water storage capacity (i.e., the maximum possible water storage after quick drainage has stopped) in an upper canopy tree in this study, because the rain events in this study were selected so that the canopy would be fully wet at the time rainfall ceased within the three criteria.

To determine the unknown parameters of Sc and Ra included in Eqs. (1) and (2), parameter determinations were performed to minimize estimation errors of the CDTcalc, i.e., to minimize

errors (Sc, Ra) $=\frac{1}{n} \sum_{i=1}^{n} \frac{\mid \text { CDTcalc }(\mathrm{Sc}, \mathrm{Ra})-\text { CDTobs } \mid}{\text { CDTobs }}$,

where $n$ is the total number of events from which CDTobs, the estimated canopy drying time by sap flow measurements, could be derived $(n=22)$. The input of $\overline{R n}, \overline{V P D}$ were the mean Rn and VPD in the period from time $A$ to time $S$.

Although this study treated $\mathrm{Ra}$ as a constant, in some studies (e.g., Schellekens et al., 2000), Ra is expressed as follows:

$\mathrm{Ra}=\frac{\left[\ln \left\{(\mathbf{z}-\boldsymbol{d}) / \mathbf{z}_{0}\right\}\right]^{2}}{k^{2} u(z)}$,

where $d$ is the zero plane displacement, $z_{0}$ is the roughness length, $k$ is the von Karman's constant and $u(z)$ is the wind speed at level $z$. As shown in Eq. (4), we can occasionally optimize $d$ and $z_{0}$ by the method proposed in this study when wind speed measurements are available. However, this study considered the estimation of Sc as a more critical issue than that of Ra, and so treated Ra as a constant because $\mathrm{Ra}$ has less impact on the reproducibility of numerical models for rainfall interception than Sc, as shown in earlier studies conducted in tropical forests (Hall et al., 1996; Manfroi, 2006).

\section{Materials and methods}

\section{Site}

This study was carried out in a lowland tropical rainforest in the Lambir Hills National Park, Sarawak, Malaysia $\left(4^{\circ} 20^{\prime} \mathrm{N}\right.$, $113^{\circ} 50^{\prime} \mathrm{E}$ ), situated $200 \mathrm{~m}$ above mean sea level, about $30 \mathrm{~km}$ southwest of Miri, Sarawak. The Park has an area of 6949 ha, $85 \%$ of which is covered by lowland mixed-dipterocarp forest that is common to Borneo (Itoh et al., 1997), with a continuous canopy height of approximately $50 \mathrm{~m}$. The leaf area index (LAl) measured with pair of plant canopy analyzers (LAI2000, Li-Cor, Lincoln, NE) every $5 \mathrm{~m}$ on a $30 \mathrm{~m} \times 30 \mathrm{~m}$ subplot was approximately $6.2 \mathrm{~m}^{2} \mathrm{~m}^{-2}$ with a small seasonal fluctuation (Kumagai et al., 2004), and basal area was approximately $41.7 \mathrm{~m}^{2} \mathrm{ha}^{-1}$ (Manfroi et al., 2004). The park has a $49.5 \mathrm{~m}$ tree tower and a $93 \mathrm{~m}$ tall crane facility for long-term hydro-ecological studies (Nakashizuka et al., 2001).

\section{Sap flow measurements}

Sap flow measurements were conducted using the thermal heat pulse method (Swanson and Whitfield, 1981) in an upper canopy tree, Dipterocarpus pachyphyllus, of about $48 \mathrm{~m}$ with a $113.1 \mathrm{~cm}$ diameter at $1.3 \mathrm{~m}$ from the ground (DBH) adjacent to the $49.5 \mathrm{~m}$ tall tree tower. The target tree had foliage above a height of $31.2 \mathrm{~m}$ from the ground. We used a heat pulse sensor (HP-1, Hayasi Denko, Tokyo, Japan) that contains a heater probe and two thermistor probes $(2.0 \mathrm{~mm}$ in diameter, $50 \mathrm{~mm}$ in length). The heater probe was inserted radially into a main branch with a diameter of $30 \mathrm{~cm}$ in the target tree at about $35 \mathrm{~m}$ above ground level. The two thermistor probes were vertically aligned asymmetrically around the heater probe. The upper and lower probes were spaced 10 and $7 \mathrm{~mm}$, respectively, from the heater probe. The sensors were installed in holes drilled with a gauge guide into the outer xylem to a depth of $20 \mathrm{~mm}$; a depth at which sap flow velocity peaked in the radial profiles. Prior to the measurements, we determined this point in the radial profiles using two sets of sensors according to Ueda and Shibata (2002). We measured radial profiles of sap flow velocity using a set of a fixed sensor and a second set of a moving sensor to a depth of $5.0 \mathrm{~cm}$ at $0.5 \mathrm{~cm}$ intervals. A heat pulse tracer was released for $1.5 \mathrm{~s}$ every $20 \mathrm{~min}$, and the heat pulse velocity was stored in a data logger (CR10X, Campbell Scientific, Longan, USA). Continuous measurements were conducted June 2001-March 2002 and September 2003-October 2003. To account for the influence of sap flow interruption around an implanted sensor, the heat pulse velocity was adjusted to the sap flow velocity using Swanson's method (Swanson and Whitfield, 1981). To confirm the spatial representativeness of the diurnal trend of sap flow velocities measured in $D$. pachyphyllus, we made temporary measurements of sap flow velocities in the stem above the buttresses of other upper canopy trees, Dryobalanops aromatica and Shorea beccariana. These trees were located about $540 \mathrm{~m}$ northeast of the tree tower, and were trees about $53 \mathrm{~m}$ tall with a DBH of $142.7 \mathrm{~cm}$ and about $51 \mathrm{~m}$ tall with a DBH of $97.5 \mathrm{~cm}$, respectively. Foliage in the $D$. aromatica and $S$. beccariana trees were found above the heights of $34.9 \mathrm{~m}$ and $38.6 \mathrm{~m}$, respectively, from the ground. Sensors were also installed to a depth at which the sap flow velocity peaked in the radial profiles. In our samples, the peaks in the radial profiles were measured at a depth of around $2.0 \mathrm{~cm}$. Continuous measurements in these above mentioned trees were conducted September 2003October 2003. 


\section{Meteorological measurements}

Monitoring equipment was installed at the top of the $49.5 \mathrm{~m}$ tree tower. Air temperature and relative humidity were measured using a thermohygrograph (HMP45A, Vaisala, Helsinki, Finland). Net radiation ( $\mathrm{Rn})$ was calculated using downward and upward short-and long-wave radiation measured using solarimeters (MS402, EKO, Tokyo, Japan) and infrared radiometers (MS202F, EKO), respectively. Wind speed was measured using a three-cup anemometer (AC750, Makino, Tokyo, Japan). Rainfall was measured using a tipping-bucket rain gauge $(20 \mathrm{~cm}$ in diameter and $0.5 \mathrm{~mm}$ in tip resolution; Ohta Keiki, Tokyo, Japan).

\section{Determination of Sc and Ra by conventional methods}

To confirm the accuracy of our estimations, we compared our estimations with Sc and Ra determined by two conventional methods. Canopy water storage capacity $(\mathrm{Sc})$ was determined by a mean method (e.g., Klaassen et al., 1998). In this site, throughfall and stemflow measurements for the mean method were conducted in the area surrounding the crane, being a 4 ha study plot divided into 400 subplots of $10 \mathrm{~m} \times 10 \mathrm{~m}$. In a fixed subplot of the 400 subplots, stemflow generated by all trees (78 trees) with $\mathrm{DBH}>1 \mathrm{~cm}$ and throughfall at 20 points were continuously observed on a daily basis for 3 years. As well, daily measurements of throughfall at another 22 subplots, periodically relocated in the 4 ha plot, were conducted for the same 3-year study period using a set of 20 throughfall collectors. From these measurements, we estimated throughfall and stemflow at the 4 ha study plot on an event basis; a value of $\mathrm{Sc}=0.65 \mathrm{~mm}$ was derived from the relationship between net rainfall (throughfall + stemflow) and rainfall (Manfroi et al., 2006). A more complete description of the intensive measurements of throughfall and stemflow at the 4 ha plot is available in Manfroi et al. (2004, 2006).

Aerodynamic parameters, zero plane displacement $(d)$ and roughness length $\left(z_{0}\right)$ for Ra (see Eq. (4)) were determined independently by wind profile analysis using a standard least-squares approach (e.g., Lafleur, 1992). At the $93 \mathrm{~m}$ tall crane located about $540 \mathrm{~m}$ northeast of the tree tower, wind speed profiles were measured at 10-min intervals using three-cup anemometer (AC750, Makino) mounted at respectively 60, 76, and $93 \mathrm{~m}$ above ground level $(10,26$, $43 \mathrm{~m}$, respectively, above the canopy). The bulk Richardson number $\left(R i_{\mathrm{B}}\right)$ was used to select wind speed profiles for near-adiabatic conditions $\left(0.0<R i_{\mathrm{B}}<0.1\right)$ according to Komatsu et al. (2005); values of $d=37.8 \mathrm{~m}$ and $\mathrm{z}_{0}=1.73 \mathrm{~m}$ were computed. In this study, Ra was calculated from Eq. (4) using the derived aerodynamic parameters and the mean wind speed during the period of CDTobs, which was measured at the top of the tree tower.

\section{Results and discussion}

\section{Estimation of Sc and $\mathrm{Ra}$}

To determine the optimal parameter set of Sc and Ra by trial and error, contour lines of errors computed by
Eq. (3) as shown in Fig. 1, were used. The parameters Sc and $\mathrm{Ra}$ were examined in the ranges of $\mathrm{Ra}$ and $\mathrm{Sc}$ that have been reported in broad-leaves forests in tropical and temperate regions (Lloyd et al., 1988; Klaassen et al., 1998; Schellekens et al., 2000). Errors were sensitive to changes in Sc, while they were insensitive to Ra. Errors were minimal when $7 \leqslant \mathrm{Ra} \leqslant 60 \mathrm{~s} \mathrm{~m}^{-1}, 0.5 \leqslant \mathrm{Sc} \leqslant 0.9 \mathrm{~mm}$. The minimum error was derived when the parameter set $(\mathrm{Ra}, \mathrm{Sc})$ was $(14,0.7)$.

The value, $\mathrm{Sc}=0.7 \mathrm{~mm}$, estimated in this study corresponded well to the value of $0.65 \mathrm{~mm}$ determined by the independent method conducted at the 4 ha study plot. The estimated Ra with minimum error $\left(=14 \mathrm{~s} \mathrm{~m}^{-1}\right)$ was within the range of the most frequently calculated values based on wind profile measurements using the 93-m tall crane facility at the 4 ha study plot, which was observed to be in a range between 10 and $30 \mathrm{~s} \mathrm{~m}^{-1}$ (Fig. 2). The range of estimated $\mathrm{Ra}$ with errors $\leqslant 0.4$ (i.e., $7 \leqslant \mathrm{Ra} \leqslant 60 \mathrm{~s} \mathrm{~m}^{-1}$; Fig. 1) also corresponded well to the range of observed $\mathrm{Ra}$, which was between 0 and $50 \mathrm{~s} \mathrm{~m}^{-1}$ (Fig. 2). These results showed that Sc and a general value of Ra produced by our method using CDTobs corresponded well to the values derived at a 4 ha study plot-scale at this site.

\section{Spatial representativeness of an upper canopy tree}

The estimated parameters Sc and $\mathrm{Ra}$ based on CDTobs seemed to be spatially representative at a stand-scale (i.e., a 4 ha study plot-scale), although CDTobs was derived from the sap flow velocities measured in a main branch about $35 \mathrm{~m}$ above ground level. In this study, cross correlation analysis showed high correlations among the sap flow velocities measured in the three upper canopy trees (mean $r=0.96$ at zero time lags). That is, the diurnal courses of the sap flow velocities measured in the branch exhibited a remarkable concordance with those in the stem above the buttresses of other upper canopy trees that stood apart. Also, cross correlation analysis was performed for sap flow

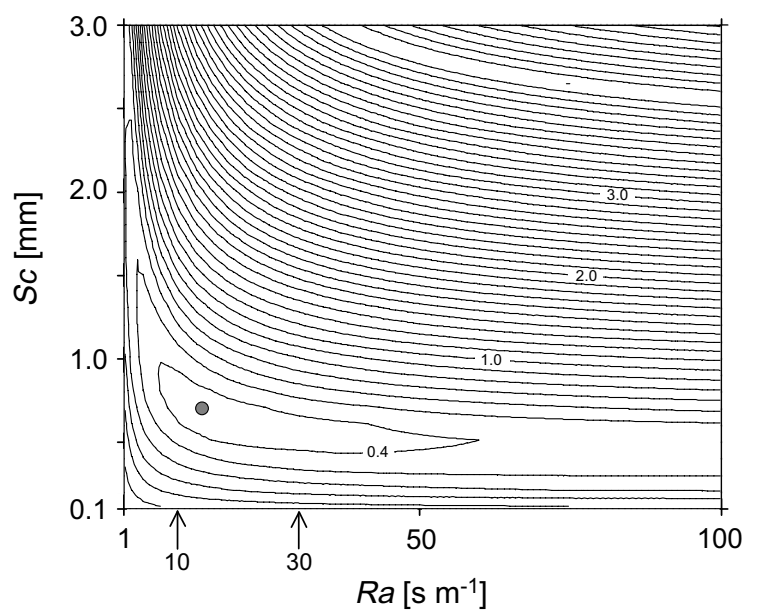

Figure 1 Contour lines of errors computed by Eq. (3) with Sc on the abscissa and Ra on the ordinate. Gray dot represents the point with computed minimum error. 10 and $30 \mathrm{~s} \mathrm{~m}^{-1}$ indicated by the vertical arrows represent the range of $\mathrm{Ra}$ most frequently measured (see Fig. 2). 


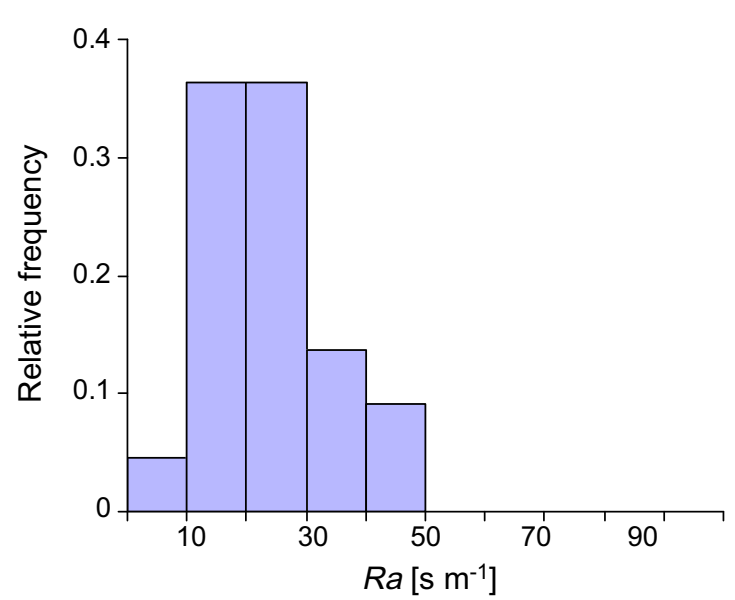

Figure 2 Relative frequency of measured Ra calculated from Eq. (4) using $d=37.8 \mathrm{~m}, \mathrm{z}_{0}=1.73 \mathrm{~m}$, and mean wind speed during the period of CDTobs $(n=22)$.

velocities measured in the three upper canopy trees in respect to the stand-scale transpiration, calculated by the Penman-Monteith transpiration model, calibrated and validated by water vapor fluxes measurements conducted using the 93-m tall crane facility (Kumagai et al., 2004). Consequently, maximum correlations were derived at a time lag of zero with mean $r=0.93$ (Kume et al., accepted for publication). As well, transpiration from upper canopy trees is thought to contribute most of the total stand-scale transpiration at this site (Kumagai et al., 2006). This means that the diurnal trend of sap flow velocities in an upper canopy tree can be regarded as representing the diurnal trend of stand-scale transpiration. Furthermore, CDTobs derived from sap flow velocities measured in D. aromatica and $S$. beccariana corresponded well to that of the main branch in D. pachphyllus. We found strong linear relationships between CDTobs in D. aromatica (CDTa), S. beccariana $(C D T b)$, and $D$. pachphyllus (CDTp) $(C D T a=1.01 \times C D T p$, $R^{2}=0.97, n=7, p<0.001 ; C D T b=0.97 \times C D T p, R^{2}=0.97$, $n=7, p<0.001)$. Therefore, CDTobs derived from the diurnal trend of sap flow velocities in an upper canopy tree can represent the whole canopy drying time, and Sc and Ra estimated from CDTobs agree with Sc and Ra determined independently at a stand-scale.

In our sample trees, surprisingly, time lags between sap flow and transpiration were insignificant, and the diurnal trend of sap flow velocities measured in stems corresponded well to that of canopy-scale transpiration without considering the time lags, despite being 50-m tall emergent trees (Kume et al., accepted for publication). This implies that internal water storage was insignificant due to the shallow sap wood in our sample trees. Actually, for the radial profiles of sap flow velocities in our sample trees, we measured peaks in the radial profiles at a depth of around $2.0 \mathrm{~cm}$, while there was nearly zero sap flow at a depth of $5.0 \mathrm{~cm}$. On the other hand, James et al. (2002) found active sap flow even at the depth of $25 \mathrm{~cm}$ in the radial profiles of some emergent trees in a neo-tropical rainforest, where remarkable time lags between sap flow and transpiration ranging 1-2 $\mathrm{h}$ were reported (Goldstein et al., 1998). The difference of the time lags between different species can affect the representativeness of the estimated canopy drying times. Thus, when the method proposed in this study is applied to other forest sites, time lags between sap flow and transpiration and the spatial representativeness of the diurnal trend of sap flow velocity need to be carefully examined before any application of our method.

\section{Practical limitations of our simple method}

Fig. 3 shows the relationships between CDTobs and CDTcalc using the optimal parameter set of $(\mathrm{Sc}=0.7 \mathrm{~mm}$, $\mathrm{Ra}=14 \mathrm{~s} \mathrm{~m}^{-1}$ ) and Eq. (1). Samples mostly approach the $1: 1$ line and 15 among the 22 samples differed by $<1 \mathrm{~h}$ (Fig. 3). However, three samples had significantly shorter CDTcalc than CDTobs when CDTobs were larger than $250 \mathrm{~min}$. Two reasons might have caused such a discrepancy.

First, it can be thought that CDTobs were sometimes overestimated with CDTobs $>250 \mathrm{~min}$. This study assumed that the lower sap flow velocities after rainfall than those that could be expected on bright days were due to canopy wetness. While, in the rain events with CDTobs $>250 \mathrm{~min}$, net radiation and VPD increased slowly after rainfall due to cloud cover (Fig. 4b-d). In this case, using the differences in diurnal variations in sap flow velocities on a rainy day vs. bright days, it is difficult to detect the effects of canopy wetness on transpiration since the decrease in sap flow velocities after rainfall can be caused by low solar radiation and VPD rather than just canopy wetness. This problem may be overcome by comparing the sap flow velocity measured on a rainy day with that modeled on the basis of solar radiation and VPD (e.g., Komatsu et al., 2006).

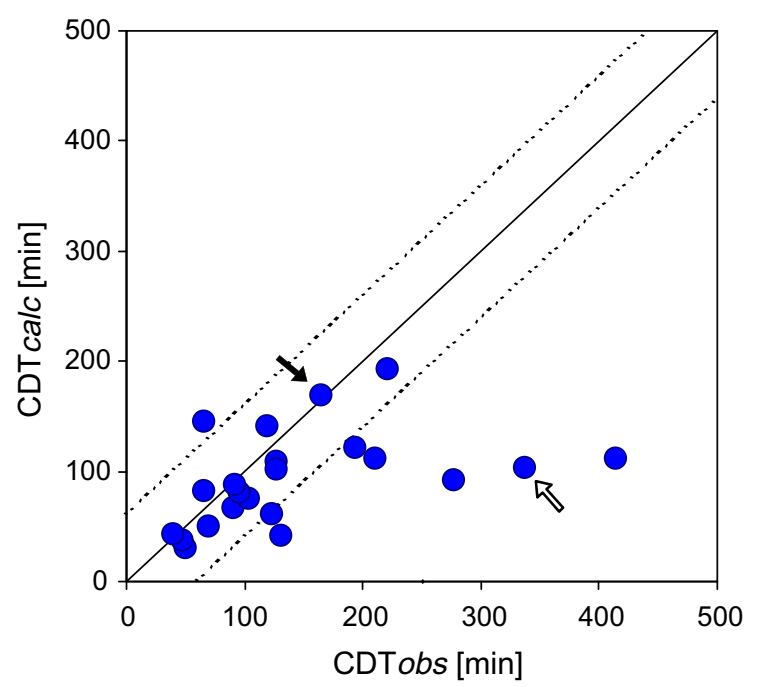

Figure 3 Relationship between estimated canopy drying time by sap flow measurements (CDTobs) and calculated canopy drying time (CDTcalc) using the optimal parameter set $\left(\mathrm{Ra}=14 \mathrm{~s} \mathrm{~m}^{-1}, \mathrm{Sc}=0.7 \mathrm{~mm}\right)$ and Eqs. (1) and (2). The solid line indicates $C D T c a l c=C D T o b s$. Dotted lines indicate the difference between CDTcalc and CDTobs $=1 \mathrm{~h}$. Open and black arrows represent the event for which diurnal variations in sap flow velocities and meteorological elements are shown in Fig. 4. 

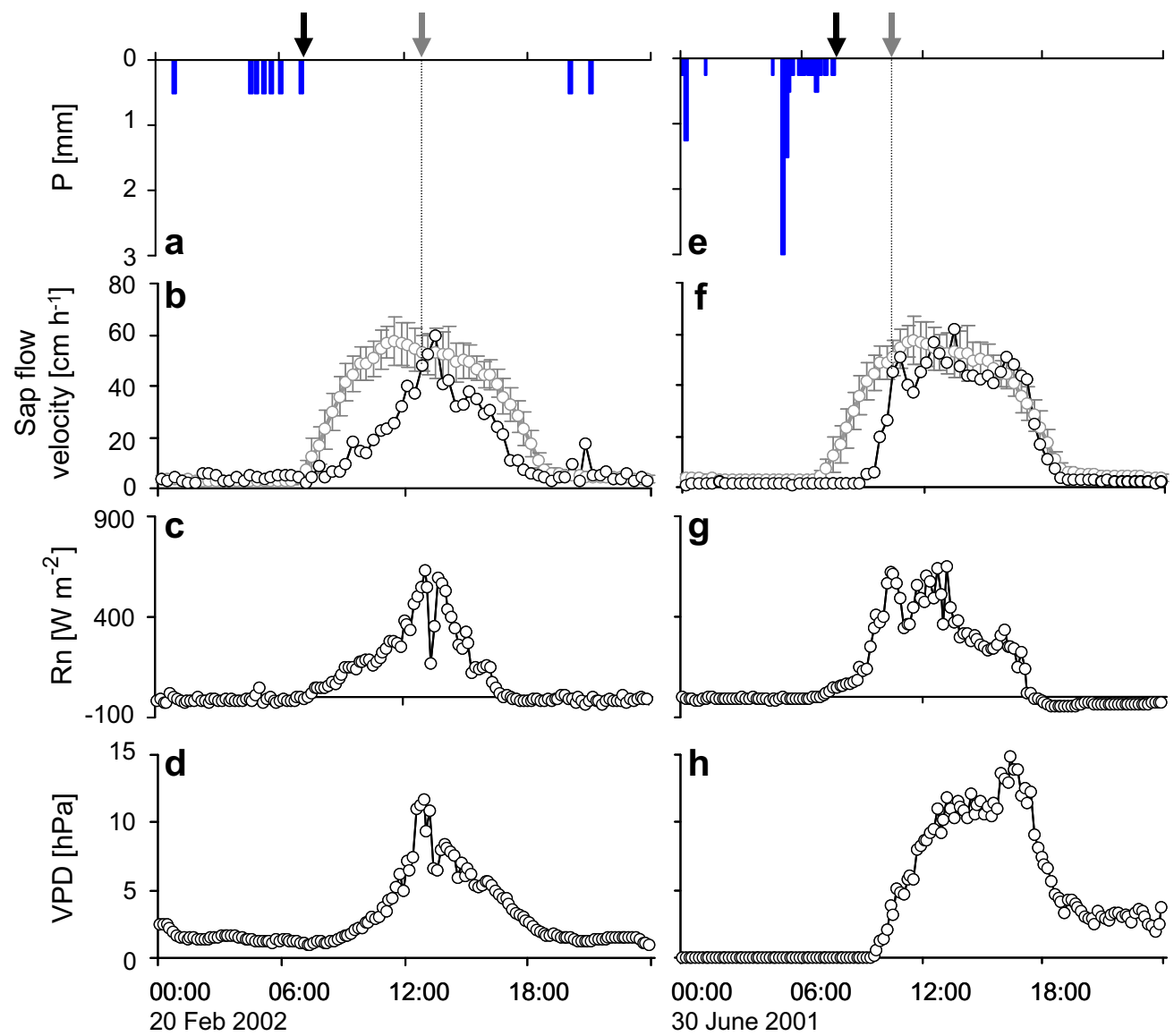

Figure 4 Typical diurnal courses for an event that showed less predictability of CDTcalc (left column) and greater predictability of CDTcalc (right column); indicated using open and black arrows in Fig. 3 , respectively. (a and e) Rainfall (P); (b and f) Sap flow velocity; (c and g) Net radiation (Rn); and ( $d$ and h) Vapor pressure deficit (VPD), respectively. Sap flow velocities averaged over 20 bright days are also shown with standard deviations indicated by vertical bars. The vertical black and gray arrows represent the time of rainfall cessation (time $A$ ) and the time when sap flow velocity after rainfall exceeded the average minus the standard deviation of the sap flow velocity averaged over 20 bright days (time S), respectively.

Second, this study assumed that evaporative energy was completely consumed to evaporate water storage on leaves during the canopy drying period and that transpiration would be negligible during that period. However, there is a transitional period when interception and transpiration occur simultaneously on a canopy as the canopy is drying gradually after rainfall, starting from the top and transpiration starts on the dry portion of canopy (Watanabe and Mizutani, 1996; Takanashi et al., 2003). When transpiration occurs significantly during the canopy drying period, significant evaporative energy is also consumed for transpiration (e.g., Rutter et al., 1975; Bosveld and Bouten, 2003). Therefore, the assumption in this study results in an underestimation of CDTcalc as transpiration is not actually negligible; thus the assumption cannot be applied in events where sap flows significantly occur over a long time during CDTobs (Fig. 4b). Furthermore, this method cannot be applied to tropical rainforests where rainfall interception is controlled by multiple processes that are under maritime influences, since the Penman-Monteith evaporation model has been shown as failing to predict the observed rainfall interception in such a forest (Schellekens et al., 2000).
On the other hand, Fig. $4 \mathrm{f}$ shows typical diurnal courses of sap flow velocity for an event that showed the greater predictability of CDTcalc than did other events at this site. Fig. $4 \mathrm{e}-\mathrm{h}$ shows that sap flow velocity after rainfall increased as abruptly as Rn and VPD, and that the period when sap flows significantly occurred during CDTobs was less than $1 \mathrm{~h}$. The practical limitations of this method can therefore be overcome in events where cloudy weather after rainfall abruptly becomes sunny. Such abrupt weather changes often occur in tropical regions because rainfall with small spatial and temporal scales occurs more frequently in tropical than other climatic regions (e.g., Houze et al., 1981). Thus we conclude our simple method for estimating Sc in this study is applicable in tropical regions with these specific rainfall characteristics.

However, it is remains unknown whether our method, which we continue to develop and refine, can at this point be applied to other forests. Sap flow measurements have been conducted in intact tropical and man-made forests in Southeast Asia, Amazon, and Central American regions (e.g., Granier et al., 1996; Cienciala et al., 2000; Goldstein et al., 1998; Kume et al., 2007a). By re-analyzing sap flow 
data from these forests, the validity of our method could be tested and strengthened.

\section{Acknowledgements}

This work was supported by the CREST program of the JST (Japan Science and Technology Corporation). We would like to express our appreciation to Ms. Lucy Chong of the Forest Research Center, Sarawak Forestry Corporation, and Tohru Nakashizuka of Tohoku University for their sincere cooperation with our work in Lambir. Some of the equipment used was installed by Dr. Shinji Sawano of the National Institute for Agro-Environmental Sciences. We also thank assistant Prof. Norifumi Hotta of the University of Tokyo and Dr. Hikaru Komatsu of Kyushu University for their helpful comments.

\section{References}

Bosveld, F.C., Bouten, W., 2003. Evaluation a model of evaporation and transpiration with observations in a partially wet douglas-fir forest. Boundary Layer Meteorology 108, 365-396.

Bouten, W., Schaap, M.G., Aerts, J., Vermetten, A.W.M., 1996. Monitoring and modeling canopy water storage amounts in support of atmospheric deposition studies. Journal of Hydrology 181, 305-321.

Cienciala, E., Kucera, J., Malmer, A., 2000. Tree sap flow and stand transpiration of two Acacia mangium plantations in Sabah, Borneo. Journal of Hydrology 236, 109-120.

Goldstein, G., Andrade, J.L., Meinzer, F.C., Holbrook, N.M., Cavelier, J., Jackson, P., Celis, A., 1998. Stem water storage and diurnal patterns of water use in tropical forest canopy trees. Plant Cell and Environment 21, 397-406.

Granier, A., Huc, R., Barigah, S.T., 1996. Transpiration of natural rain forest and its dependence on climatic factors. Agricultural and Forest Meteorology 78, 19-29.

Hall, R.L., Calder, I.R., Gunawardena, E.R.N., Rosier, P.T.W., 1996. Dependence of rainfall interception on drop size. 3. Implementation and comparative performance of the stochastic model using data from a tropical site in Sri Lanka. Journal of Hydrology 185, 389-407.

Houghton, R.A., Hackler, J.L., 1999. Emission of carbon from forestry and land-use change in tropical Asia. Global Change Biology 5, 481-492.

Houze, R.A., Geotis, S.G., Marks, F.D., West, A.K., 1981. Winter monsoon convection in the vicinity of north Borneo. Part I. Structure and time variation of the clouds and precipitation. Monthly Weather Review 109, 1595-1614.

Itoh, A., Yamakura, T., Ogino, K., Lee, H.S., Ashton, P.S., 1997. Spatial distribution patterns of two predominant emergent trees in a tropical rainforest in Sarawak, Malaysia. Plant Ecology 132, 121-136.

James, S.A., Clearwater, M.J., Meinzer, F.C., Goldstein, G., 2002. Variable length heat dissipation sensors for the measurements of sap flow in trees with deep sapwood. Tree Physiology 22, 277283.

Klaassen, W., Bosveld, F., Water, E.D., 1998. Water storage and evaporation as constituents of rainfall interception. Journal of Hydrology, 36-50.

Komatsu, H., Hotta, N., Kuraji, K., Suzuki, M., Oki, T., 2005. Classification of vertical wind speed profiles observed above a sloping forest at nighttime using the bulk Richardson number. Boundary Layer Meteorology 115, 205-221.
Komatsu, H., Kang, Y., Kume, T., Yoshifuji, N., Hotta, N., 2006. Transpiration from a Cryptomeria japonica plantation. II. Responses of canopy conductance to meteorological factors. Hydrological Processes 20, 1321-1334.

Kumagai, T., Saitoh, T.M., Sato, Y., Morooka, T., Manfroi, O.J., Kuraji, K., Suzuki, M., 2004. Transpiration, canopy conductance and the decoupling coefficient of a lowland mixed dipterocarp forest in Sarawak, Borneo: dry spell effects. Journal of Hydrology $287,237-251$.

Kumagai, T., Ichie, T., Yoshimura, M., Yamashita, M., Kenzo, T., Saitoh, T.M., Ohashi, M., Suzuki, M., Koike, T., Komatsu, H., 2006. Modeling $\mathrm{CO}_{2}$ exchange over a Bornean tropical rain forest using measured vertical and horizontal variations in leaf-level physiological parameters and leaf area densities. Journal of Geophysical Research 111, D10107. doi:10.1029/2005JD00667.

Kume, T., Kuraji, K., Yoshifuji, N., Morooka, T., Sawano, S., Chong, L., Suzuki, M., 2006. Estimation of canopy drying time after rainfall using sap flow measurements in an emergent tree in a lowland mixed-dipterocarp forest in Sarawak, Malaysia. Hydrological Processes 20, 565-578.

Kume, T., Takizawa, H., Yoshifuji, N., Tanaka, K., Tanaka, N., Tantasirin, C., Suzuki, M., 2007a. Impact of soil drought on sap flow and water status of evergreen trees in a tropical monsoon forest in northern Thailand. Forest Ecology and Management 238, 220-230.

Kume, T., Komatsu, H., Kuraji, K., Suzuki, M., accepted for publication. Less than 20-min time lags between transpiration and stem sap flow in emergent trees in a Bornean tropical rainforest. Agricultural and Forest Meteorology.

Kuraji, K., Tanaka, N., 2003. Rainfall interception studies in the tropical forests. Journal of the Japan Forestry Society 85, 1828, in Japanese, with English summary.

Landsberg, J.J., Gower, S.T., 1997. Applications of Physiological Ecology to Forest Management. Academic Press, San Diego, 354 pp..

Lafleur, P.M., 1992. Energy balance and evapotranspiration from a subarctic forest. Agricultural and Forest Meteorology 58, 163175.

Liu, S., 1998. Estimation of rainfall storage capacity in the canopies of cypress wetlands and slash pine uplands in North-Central Florida. Journal of Hydrology 207, 32-41.

Llorens, P., Gallart, F., 2000. A simplified method for forest water storage capacity measurement. Journal of Hydrology 240, 131144.

Lloyd, C.R., Gash, J.H.C., Shuttleworth, W.J., 1988. The measurement and modeling of rainfall interception by Amazonian rain forest. Agricultural and Forest Meteorology 43, 277-294.

Manfroi, O.J., Kuraji, K., Tanaka, N., Suzuki, M., Nakagawa, M., Nakashizuka, T., Chong, L., 2004. The stemflow of trees in a Bornean lowland tropical forest. Hydrological Processes 18, 2455-2474.

Manfroi, O.J., Kuraji, K., Suzuki, M., Tanaka, N., Kume, T., Nakagawa, M., Kumagai, T., Nakashizuka, T., 2006. Comparison of conventionally observed interception evaporation in a $100-\mathrm{m}^{2}$ subplot with that estimated in a 4-ha area of the same Bornean lowland tropical forest. Journal of Hydrology 329, 329-349.

Manfroi, O.J., 2006. Evaluating evaporation of intercepted rainfall in a lowland tropical forest in Sarawak, Malaysia by observation and modeling. Ph.D. Thesis. The University of Tokyo, 127 pp.

Nakashizuka, T., Lee, H.S., Chong, L., 2001. Studies on canopy processes of a tropical rain forest in Lambir Hills National Park. In: Proceedings of the International Symposium, Canopy Processes and Ecological Roles of Tropical Rain Forest, pp. 2-7.

Rutter, A.J., Morton, A.J., Robins, P.C., 1975. A predictive model of rainfall interception in forests. II. Generalization of the model and comparison with observations in some coniferous and hardwood stands. Journal of Applied Ecology 12, 367-380. 
Sato, Y., Kumagai, T., Saitoh, T.M., Suzuki, M., 2004. Characteristics of soil temperature and soil heat flux within tropical rainforest, Lambir Hills National Park, Sarawak, Malaysia. Bulletin of the Institute of Tropical Agriculture, Kyushu University $27,5-63$.

Schellekens, J., Bruijnzeel, L.A., Scatena, F.N., Bink, N.J., Holwerda, F., 2000. Evapotranspiration from a tropical rain forest, Luquillo Experimental Forest, eastern Puerto Rico. Water Resources Research 36, 2183-2196.

Swanson, R.H., Whitfield, D.W.A., 1981. A numerical analysis of heat pulse velocity theory and practice. Journal of Experimental Botany 32, 221-239.
Takanashi, S., Kosugi, Y., Tani, M., Ohte, N., Yano, M., Tanaka, H., Tanaka, K., 2003. Evaporation from a Japanese cypress forest during and after rainfall. Journal of the Japan Society of Hydrology and Water Resources 16, 268-283, in Japanese, with English summary.

Ueda, M., Shibata, E., 2002. Water status of Hinoki cypress (Chamaecyparis obtusa) under reduced hydrauli conductance estimated from diurnal changes in trunk diameter. Trees 16, 523-528.

Watanabe, T., Mizutani, K., 1996. Model study on micrometeorological aspects of rainfall interception over an evergreen broad-leaved forest. Agricultural and Forest Meteorology 80, 195-214. 